\title{
O impacto da crise econômica espanhola na mão de obra imigrante
}

\author{
Nilton Cezar Pereira Pinto*
}

\begin{abstract}
Este artigo tem o objetivo de analisar a situação da mão de obra imigrante na Espanha nos últimos dez anos, vinculando-a com as transformações econômicas e sociais pelas quais o país tem passado desde meados da década de 1990, com ênfase no panorama gerado pela crise econômica que eclodiu a partir do final de 2008 e o seu impacto na situação dos imigrantes, coletivo que mais tem sofrido com o novo quadro econômico e social estabelecido com a crise. Diante da situação que a Espanha atravessa, com notável aumento do desemprego e de deterioração dos indicadores sociais, nota-se o retorno considerável de imigrantes para os seus países de origem depois de esgotarem todas as vias alternativas de permanência na Espanha. O fundamento para o desenvolvimento deste trabalho foram os dados proporcionados pelo Instituto Nacional de Estadística (INE) da Espanha, utilizando a EPA (Encuesta de Población Activa), além dos dados do Eurostat e das fontes bibliográficas citadas.
\end{abstract}

Palavras-chave: Imigração. Crise econômica. Espanha. Retorno. Desemprego.

\footnotetext{
*Universidad Rey Juan Carlos, Madrid, Espanha (niltoncpp@gmail.com).
} 


\section{Introdução}

Durante a segunda metade da década de 1990, a Espanha passou da sua condição histórica de país emissor de mão de obra para a de um país de destino para milhões de imigrantes chegados, principalmente, do Marrocos, de países latino-americanos e do Leste Europeu. No período aproximado de dez anos, boa parte desses imigrantes encontrou trabalho no setor de serviços, especialmente na construção civil, um dos setores mais dinâmicos da economia espanhola que vigorou até o início da crise econômica, em 2008.

Durante o período de piora no quadro econômico, de aumento do desemprego e crescente empobrecimento dos trabalhadores assalariados, é justamente o grupo dos imigrantes que tem a situação mais dramática, com elevadas taxas de desemprego e, como consequência direta, a necessidade de driblar a situação das mais variadas maneiras. Quando se esgotam todas as estratégias para tal fim, eles optam pelo retorno aos seus países.

\section{Contexto da atual situação econômica da Espanha}

A crise econômica que eclodiu em 2008 e seus desdobramentos durante os anos posteriores provocaram um êxodo de mão de obra espanhola para outros países. 0 binômio "crise e austeridade" deu lugar a taxas de desemprego nunca antes vistas e ao aumento alarmante da pobreza na Espanha. De acordo com os dados da EPA (Encuesta de Población Activa) do quarto trimestre de 2013 , a taxa de desemprego no país chegava a $26,03 \%$, com mais de 5,9 milhões de desempregados (Tabela 1). Enquanto a taxa de desemprego dos nacionais espanhóis se situava em $24,30 \%$, a relativa à população estrangeira alcançava $36,31 \%$, ou seja, mais de 12 pontos percentuais de diferença.

TABELA 1

Taxas de atividade e de desemprego, segundo segmentos da população Espanha - out.-dez. 2013

Em porcentagem

\begin{tabular}{lcc}
\hline \multicolumn{1}{c}{ População } & Taxa de atividade & Taxa de desemprego \\
\hline Total nacional & 59,43 & $\mathbf{2 6 , 0 3}$ \\
Homens & 65,90 & 25,31 \\
Mulheres & 53,31 & 26,87 \\
Total espanhóis & 57,27 & 24,30 \\
Total estrangeiros & 73,31 & 36,31 \\
\hline
\end{tabular}

Fonte: Instituto Nacional de Estadística.

A reforma trabalhista de 2012 teve forte impacto negativo sobre o emprego, aumentando a destruição de postos de trabalho. Para cada décimo de queda no PIB, a eliminação de empregos no conjunto dos trabalhadores aumentou 186\% em 2012 em comparação com 2009 (LAGO PEÑAS, 2013).

Entre 2008 e 2009 perderam-se três milhões de postos de trabalho. A taxa de desemprego na Espanha é a mais alta da União Europeia e a taxa de desemprego entre jovens menores de 
25 anos é a segunda depois de grega (ROCHA, 2012). Não obstante, o desemprego aumentou em todas as faixas etárias durante o período 2008-2012, golpeando com maior intensidade a população estrangeira e, sobretudo, as pessoas sem qualificação profissional.

TABELA 2

Evolução das taxas de desemprego

Países da Zona Euro - 2009-2014

\begin{tabular}{|c|c|c|c|c|c|c|}
\hline & & & & & & porcentagem \\
\hline Países & 2009 & 2010 & 2011 & 2012 & 2013 & 2014 \\
\hline Zona Euro & 9,5 & 10,1 & 10,1 & 11,3 & 12,0 & 11,2 \\
\hline Alemanha & 7,8 & 7,1 & 5,9 & 5,5 & 5,3 & 4,8 \\
\hline Áustria & 4,8 & 4,4 & 4,2 & 4,3 & 4.9 & 5,6 \\
\hline Bélgica & 7,9 & 8,3 & 7,2 & 7,6 & 8,4 & 8,5 \\
\hline Chipre & 5,4 & 6,3 & 7,9 & 11,9 & 15,9 & 16,4 \\
\hline Eslováquia & 12,1 & 14,5 & 13,7 & 14,0 & 14,2 & 12,5 \\
\hline Eslovênia & 5,9 & 7,3 & 8,2 & 8,9 & 10,1 & 9,7 \\
\hline Espanha & 18,0 & 20,1 & 21,5 & 26,01 & 26,03 & 23,6 \\
\hline Estônia & 13,5 & 16.7 & 12,3 & 10,0 & 8,6 & 6,4 \\
\hline Finlândia & 8,2 & 8,4 & 7,8 & 7,7 & 8,2 & 9,0 \\
\hline França & 9,1 & 9,3 & 9,2 & 9,8 & 10,3 & 10,2 \\
\hline Grécia & 9,5 & 12,6 & 17,7 & 24,3 & 27,3 & 26,0 \\
\hline Holanda & 3,7 & 4,5 & 4,4 & 5,3 & 6,7 & 7,2 \\
\hline Irlanda & 12,0 & 13,9 & 14,7 & 14,7 & 13,1 & 10,2 \\
\hline Letônia & 17,5 & 19,5 & 16,2 & 15,0 & 11,9 & 10,6 \\
\hline Luxemburgo & 5,1 & 4,6 & 4,8 & 5,1 & 5,8 & 5,9 \\
\hline Malta & 6,9 & 6,9 & 6,5 & 6,4 & 6,5 & 5,8 \\
\hline Portugal & 10,6 & 12,0 & 12,9 & 15,9 & 16,5 & 13,3 \\
\hline
\end{tabular}

Fonte: Eurostat.

Um aspecto central do desemprego é o sistema de proteção aos desempregados. 0 número médio de beneficiários do sistema de proteção do governo espanhol aumentou durante o biênio 2009-2010, atingindo o máximo nesse último ano. Já em 2011 começou a diminuir devido, principalmente, ao vencimento do prazo de direito ao recebimento dos benefícios sociais. Da mesma forma, registrou-se aumento progressivo do número de beneficiários do serviço assistencial, superando o número daqueles que recebiam o benefício contributivo em 2011. No que se refere à taxa de cobertura, segundo dados do Serviço Público de Emprego, houve um crescimento nos primeiros anos da crise até atingir o máximo em 2010. Posteriormente, iniciou-se uma queda contínua desta taxa até $66,5 \%$ em 2012, devido, sobretudo, ao aumento do número de pessoas com o direito ao benefício já esgotado. Trata-se, portanto, de um fenômeno grave ao comprovar que uma boa parte dos desempregados deixou de receber as ajudas sociais (ROCHA; ARAGÓN, 2012).

Diante desse contexto, não é de se estranhar o aumento da pobreza na Espanha, demonstrado, entre outros, pelo fato de que 476.000 famílias tinham todos os seus membros desempregados em 2012. Entre 2004 e 2011, a taxa de pobreza cresceu três pontos percentuais e chegou a $21,8 \%$, levando-se em conta que o marco de limite da 
pobreza diminuiu, o que implica que os pobres são ainda mais pobres, embora seu número e proporção sobre o conjunto da população avancem mais lentamente no tempo (FUNDACIÓN 1ำ DE MAYO, 2012).

Os lares com dificuldades para atravessar o mês passaram de 26,2\% em 2011 para $31,85 \%$ em 2012. Além do crescimento da pobreza, outros indicadores davam visibilidade à deterioração social, que afeta algo tão básico como a alimentação. Entre 2010 e 2011, o consumo de alimentos reduziu-se em $0,7 \%$ acompanhado da piora na qualidade da alimentação. Tome-se como exemplo o consumo de frango, porco, vaca ou cordeiro, que foi substituído por outras carnes menos elaboradas. Também diminuiu o consumo de produtos como azeite, ovos, leite e frutas frescas (ESPANHA, 2012). Igualmente, a denominada pobreza energética impediu que $10 \%$ dos lares espanhóis se mantivessem com temperaturas adequadas durante os meses de inverno em 2010. Essa porcentagem disparou para $54 \%$ no caso de lares de pessoas idosas. A pobreza energética afeta a saúde e proporciona o aparecimento de doenças respiratórias, como asma e bronquite, e cardiovasculares. Estimam-se, como causa de morte prematura, entre 2.300 e 9.300 óbitos, o que supera o número de vítimas de acidentes de trânsito em 2011. A crise aumentou este tipo de pobreza e elevou sua incidência entre as pessoas desempregadas (ASOCIACIÓN DE CIENCIAS AMBIENTALES, 2012).

Muitos são os diagnósticos sobre a atual situação que preveem em até duas décadas o tempo necessário para recuperar o bem-estar de 2008, ano prévio à crise econômica. Ou seja, as consequências da grande recessão podem ser comparadas com o período da Guerra Civil, quando os níveis salariais dos anos 1930 só se recuperaram duas décadas mais tarde.

Para compreender o fenômeno das migrações na Espanha, é necessário analisar o papel central desempenhado pelo mundo do trabalho. A tradição espanhola como país de refúgio e asilo é escassa. Ademais, as migrações reestruturam as forças de trabalho e o mercado laboral em todos os países onde têm ocorrido com maior incidência ao longo da história.

Os aspectos de caráter trabalhista ou econômico, como podem ser tipificados os deslocamentos de mão de obra em busca de emprego para fugir da pobreza, foram decisivos na Espanha tal como admitia Consuelo Rumí, secretária de Estado de Inmigración y Emigración:

Neste começo de século, as migrações são fundamentalmente econômicas, sua ordenação precisa ter como eixo central as demandas dos mercados de trabalho [...]. A dimensão laboral é, portanto, um elemento central que estava desprezado e agora se tornou o eixo principal da política de imigração (RUMI, 2006, p. 28).

A situação da economia explica a chegada ou o êxodo de migrantes como fator de atração ou de expulsão. A oferta de emprego gerada torna-se atrativa, da mesma forma que a recessão reduz a oferta de emprego, estimulando o êxodo para outros países. Nesse caso, os trabalhadores enfrentam dificuldades para manterem seus postos de trabalho, chegam menos imigrantes e alguns abandonam o país. Paralelamente a isso, como vem ocorrendo, emigram os trabalhadores nativos. No entanto, convém considerar 
também os perfis sociológicos e culturais dos trabalhadores e suas expectativas quanto ao estilo de vida a que aspiram. Assim, se o fator econômico é decisivo, outros incentivos também influem na chamada nova mobilidade. Por exemplo, no caso de determinado grupo de trabalhadores altamente qualificados, como os pesquisadores, há fatores como a procura de entornos diferentes: mais saudáveis, menos congestionados de população, com baixos índices de criminalidade, que tragam mais qualidade de vida, que favoreçam a realização pessoal e a ascensão social ou que disponham de melhores infraestruturas para a atividade investigadora. No entanto, este grupo de motivações ganha destaque em países desenvolvidos ou em situações de crescimento econômico; mas inclusive nesses casos também existe um componente econômico (ALAMILLOS, 2012) que pode ser ilustrado com o seguinte exemplo, extraído da imprensa especializada: dois jovens espanhóis emigram para a Finlândia aproveitando um programa de voluntariado europeu para jovens entre 18 e 30 anos. Satisfeitos com a experiência de morar num ambiente totalmente diferente, decidem estabelecer-se no país porque na Espanha estavam desempregados (ESPAÑOLES EN FINLANDIA, 2010).

Levando-se em conta a centralidade do trabalho nos movimentos migratórios a partir de um ponto de vista explicativo, é preciso acrescentar que também exercem influência fatores como a existência de uma cultura de emigração ou a capacidade dos governos para condicionar, por meio de suas políticas, as decisões dos que desejam se deslocar.

O período em que a Espanha se tornou um país de acolhida de imigrantes é relativamente curto: da segunda metade da década de 1980, coincidindo com a entrada do país na Comunidade Econômica Europeia, até 2007. Esse ano marca um divisor de águas nessa curta história que pode ser dividida em três etapas.

A fase inicial começa, como mencionado anteriormente, na metade dos anos 1980 e termina pouco antes do começo do século XXI. Naquela altura, a imigração representava apenas $2,5 \%$ da população e não chegava a um milhão de pessoas. A segunda etapa denomina-se década prodigiosa da imigração e vai de 1999 até 2008.

Vejamos alguns dados: em 2009 o número de pessoas nascidas no estrangeiro beirava os 6,5 milhões, que conviviam com 40,3 milhões de nativos. A proporção de imigrantes chegava a quase $14 \%$ da população. 0 ritmo de chegadas alcançou o apogeu entre 2001 e 2004, embora em termos absolutos as entradas de 2007 foram as mais numerosas. Foi um período de crescimento sustentado e imprevisto da população imigrante, que finalizou com a eclosão da crise econômica. Dadas suas características, a economia espanhola foi muito intensiva em força de trabalho, além de predominante em setores de elevada absorção de imigrantes, como a construção civil, o serviço doméstico, o cuidado de pessoas dependentes, a hotelaria, a agricultura intensiva, a colheita de frutas e verduras.

A terceira fase inicia-se em 2008, quando a chegada de imigrantes ia diminuindo e a população imigrante já estabelecida enfrentava o período de crise, fazendo uso de diferentes estratégias. 


\section{Efeitos da crise sobre a imigração}

Os efeitos da crise sobre a imigração começam a se manifestar a partir do último trimestre de 2008 com o aumento do desemprego, a queda da população imigrante, a perda das permissões de trabalho e residência - ocasionada por desemprego prolongado - e a entrada de imigrantes na economia informal. De acordo com a EPA (Encuesta de Población Activa) do segundo trimestre de 2008, a taxa de desemprego entre os estrangeiros da União Europeia era de $15,3 \%$ e a da dos extracomunitários correspondia a 17\%. Nesse momento, a taxa de desemprego dos cidadãos espanhóis era de 9,3\%. Quatro anos mais tarde, as taxas de desemprego tinham aumentado para $29,7 \%$ no caso dos estrangeiros comunitários, $38,7 \%$ entre os extracomunitários e $22,7 \%$ entre os espanhóis. Ou seja, enquanto a taxa de desemprego da população espanhola cresceu 13,3 pontos percentuais nesse período, a dos estrangeiros comunitários aumentou 14,4 pontos e a dos extracomunitários ampliou-se em $21,7 \%$, demonstrando que os trabalhadores estrangeiros, quer de um grupo, quer de outro, são os mais castigados pela crise e recessão.

É importante destacar o primeiro trimestre de 2009. Nesse período, o desemprego atingiu a marca de $16 \%$ entre a população espanhola e de $28 \%$ entre os estrangeiros. Tal momento é importante porque o seguro-desemprego alcançou a marca de um milhão de desempregados entre os imigrantes e representa o ponto de partida para o aumento da taxa de desemprego entre a população imigrante. Por outro lado, esse período permite constatar a rapidez da destruição de emprego entre os imigrantes, já que tal destruição afetou de maneira intensa e primeiramente os trabalhadores temporários e a temporalidade do trabalho dos imigrantes é duas vezes superior à dos espanhóis. Como consequência, chama atenção a redução da taxa de temporalidade desde 2007 - quando era de $32 \%$ - entre os grupos tanto de imigrantes quanto de espanhóis não porque a situação do desemprego tenha melhorado, mas sim porque a diminuição e a destruição de emprego em tempos de crise afetam de maneira imediatamente o emprego temporário.

Para uma visão mais ampla a respeito dos efeitos da crise sobre a população imigrante, tomemos os dados do INE (Instituto Nacional de Estadística) do censo de $1^{\mathfrak{0}}$ de janeiro de cada ano. Em 2008, a população total na Espanha era de 46.157.822, aumentando, quatro anos mais tarde, para 47.265.321, ou seja, um acréscimo de pouco mais de 1.107 .000 pessoas. Entretanto, em 2013, a população retraiu-se para 47.059.533, o que significa uma redução de 205.788 pessoas com relação ao ano imediatamente anterior. Esta queda no número de habitantes deve-se, principalmente, ao decréscimo da população estrangeira, que, em 2008, chegava a 5.268.762 pessoas, passando para 5.736.258 em 2012 e 5.520 .133 em 2013. Em termos regionais, entre 2008 e 2012, aumentou o número de estrangeiros procedentes da União Europeia, África, América do Norte, América Central e Caribe. No oposto, diminuiu o da América do Sul. Nesse mesmo período, entre as dez primeiras colônias extracomunitárias, aumentou o número de nacionais procedentes da Ucrânia, Marrocos e República Dominicana. Houve diminuição do número de nacionais 
da Argentina, Bolívia, Brasil, Colômbia e Equador. Finalmente, o número de estrangeiros de nacionalidade peruana permaneceu estável. 0 balanço do conjunto é a redução da população registrada procedente da América do Sul, região de onde vinha o maior número de imigrantes.

\section{Fluxos de emigração}

Se, em vez do Censo, for utilizada a série 2010-2011 do estudo Flujos de emigración e inmigración por país de nacimiento, elaborado pelo Instituto Nacional de Estatística (INE), observa-se que nesse primeiro ano emigraram 363.476 pessoas cujo país de nascimento não era a Espanha. No entanto, imigraram 442.130 pessoas, o que significa que o saldo migratório de estrangeiros, segundo o país de nascimento, foi positivo em 78.654 pessoas. Já em 2011, emigraram 445.271 (sem contar os espanhóis de nascimento) e imigraram 429.205, representando desta vez um saldo migratório negativo de 16.066 pessoas. Os fluxos também coincidem com o Censo no sentido de que são os países da América do Sul (Argentina, Bolívia, Colômbia, Brasil e Equador) os que oferecem saldos migratórios negativos.

Esta diminuição deve-se a três motivos:

- a população da América do Sul obtém a nacionalidade espanhola por residência com certa facilidade depois de dois anos de residência legal, enquanto outras nacionalidades precisam esperar até dez anos;

- há pessoas que retornam para os seus países graças ao sistema de retorno com capitalização ou retorno humanitário. Embora as pessoas que escolham tais programas de retorno voluntário não sejam muitas, há os que retornam por sua própria conta. Apesar do número reduzido, os imigrantes são o grupo majoritário que abandona a Espanha nesse período;

- além dos elementos anteriormente citados com relação à população latino-americana, um terceiro fator que deve ser levado em conta é a violência com a qual o desemprego penetra na população imigrante. Segundo a EPA, ${ }^{1}$ em 2011, 32,2\% dos estrangeiros estavam desempregados, contra $21,6 \%$ dos espanhóis. A taxa de desemprego entre o conjunto da população imigrante era de $32,2 \%$ no geral, enquanto entre a população de origem africana subia para 50,5\% também em 2011.

\section{Fuga de mão de obra para o exterior}

Como se vê, à medida que a crise vai avançando, diminuem as chegadas e aumentam as saídas. A maioria dos que saíram do país era composta por estrangeiros que vieram para

\footnotetext{
${ }^{1}$ EPA - Encuesta de Población Activa é um estudo estatístico que visa recolher dados sobre o mercado de trabalho na Espanha, sendo utilizado para calcular a taxa de desemprego em todos os países da União Europeia.
} 
a Espanha num período de forte imigração, que vai de 1998 a 2007. Muitos tinham obtido a nacionalidade espanhola e, nesse grupo, os mais numerosos eram os latino-americanos, que, como já mencionado, obtêm-na com certa facilidade após dois anos de residência legal. A nacionalidade é um recurso de primeira magnitude que se ativa em determinados momentos e permanece latente em outros.

Tanto no fluxo de entrada como no de saída, o protagonismo dos estrangeiros é destacado, enquanto os espanhóis, e entre eles os nascidos na Espanha, têm uma relevância quantitativa muito baixa. Na análise dos dados do INE, constata-se que o número de nativos que emigram começa a aumentar de forma contínua desde 2004 , quando a economia e o nível de emprego ainda se encontravam em forte crescimento. Tal como visto anteriormente, entre $1^{0}$ de janeiro de 2009 e $1^{\circ}$ de janeiro de 2013, o número de espanhóis que residem no estrangeiro aumentou em 459.557 pessoas. No entanto, durante esse mesmo período, o número de espanhóis de nascimento aumentou apenas em 39.912 pessoas. Atentando-se na já mencionada série 2010-2011 dos fluxos de emigração e imigração por país de nascimento, observa-se que, nesse primeiro ano, dos 403.012 que emigram para o estrangeiro, apenas 39.539 são espanhóis. Já em 2011, 62.469 espanhóis de nascimento saíram para o exterior, de um total de 507.740.

Os dados demonstram dois fenômenos. Em primeiro lugar, a emigração, em sua maioria, é um fenômeno dos imigrantes estrangeiros que retornam para os seus países de origem ou então optam por ir para um terceiro país em busca de emprego devido à crise. Em segundo lugar, entre os estrangeiros, o saldo migratório negativo só ocorre a partir de 2011, o que demonstra uma grande capacidade de resistência diante da crise, apesar de ser o grupo mais vulnerável à situação de desemprego.

Por outra parte, em novembro de 2012, o INE oferecia projeções de população para o período 2012-2052. A propósito disso, o demógrafo Joaquín Recaño afirmava que "a chave e a grande incógnita é a emigração [...]. Instalou-se um nível de emigração dificilmente sustentável”. Segundo Recaño, é possível que os dados estejam inchados em parte pela limpeza do Censo, quando os estrangeiros devem atualizar suas inscrições e, ao não fazerem, são apagados do sistema (NOGUEIRA, 2012). Neste sentido, é importante observar que, desde há algum tempo, os dados do Censo podem ser utilizados pela Polícia e que, por outro lado, o recenseamento não surte nenhum efeito sobre o acesso aos sistemas educativo e de saúde para os imigrantes irregulares. Por esta razão, é primordial que os imigrantes renovem sua inscrição no Censo ou não façam uma inscrição inicial nos mesmos.

O fato de uma porcentagem superior de imigrantes do que de espanhóis emigrar nesta situação de crise econômica tem a ver com pelo menos três fatores:

- apenas uma pequena parte dos imigrantes em situação social de desemprego contribuiu com tempo suficiente para ter direito a receber o seguro-desemprego;

- a importância das redes de relações não é um fenômeno constante, mas sim variável, que depende das sociedades e das diferentes circunstâncias históricas. Neste contex- 
to, parece claro que o capital constituído pelas relações sociais é muito importante, sobretudo, se os envolvidos são pessoas que estão em situação de imigração, tendo inclusive mais importância do que quando as pessoas enfrentam outras circunstâncias. No entanto, atualmente é evidente que as redes sociais formadas por imigrantes dentro da Espanha não são muito extensas e nem contam com uma rede familiar com recursos suficientes para sustentar ou dar apoio a pessoas adultas desempregadas.

- é fundamental o impacto brutal do desemprego sobre as populações imigrantes. preciso considerar que a situação laboral dos imigrantes sempre se caracterizou pela temporalidade e instabilidade dos empregos. No entanto, tal temporalidade pode repercutir de forma diferente, dependendo da situação (de crise ou de crescimento econômico).

No primeiro caso, em que o número de empregos é abundante, o efeito da instabilidade e da temporalidade, que implica uma rotatividade dos postos de trabalho, faz com que os períodos livres entre um trabalho e outro sejam curtos, sendo possível se falar de uma situação de pleno emprego. Já a situação de crise traz consigo uma diminuição da oferta de emprego, tornando mais longos os períodos entre a realização de um trabalho e de outro.

Desse modo, os períodos de desemprego se ampliam e, inclusive, adquirem um caráter de permanência ou semipermanência. Portanto, torna-se necessário analisar a situação de emprego/desemprego desses imigrantes, pois os fenômenos migratórios são absolutamente incompreensíveis sem uma compreensão do mercado de trabalho.

Os imigrantes chegados à Espanha encontraram emprego em setores de atividade com postos de trabalho não ocupados por trabalhadores nativos e, portanto, havia uma demanda de mão de obra. Entre 1996 e 2007, a economia espanhola criou quase 8 milhões de empregos, passando de 12,6 milhões de ocupados em 1996 para 20,5 milhões no segundo trimestre de 2007 . Isso representa mais de $40 \%$ do emprego gerado em todos os países da OCDE nesse mesmo período.

A mão de obra estrangeira desempenhou papel fundamental neste período de bonança econômica. No final de 2001, o número de afiliados à Seguridade Social estava em torno de 600.000, algo menos de 4\% dos trabalhadores inscritos no sistema. No final de 2007, o número de afiliados estrangeiros havia aumentado para quase 2 milhões - 10,3\% do total de inscritos. Apesar da crise econômica, no começo de 2010, o número de estrangeiros era de 1,9 milhão (10,5\% do total de afiliados). Ou seja, a chegada e o emprego dos imigrantes não trouxeram consigo uma diminuição da quantidade de trabalhos ocupados pelos espanhóis. Ao contrário, os imigrantes aumentaram a força de trabalho disponível, trazendo consigo um crescimento do emprego em geral. Em 2005, a criação de emprego era de $3,1 \%$. Tal fato, somado ao crescimento da população de trabalhadores, permitiu reduzir o número de desempregados cuja média era de $9,2 \%$. Outro efeito da chegada dos imigrantes foi a inclusão das mulheres no mercado de trabalho formal, que aumentou de maneira excepcional. 
Entre 1995 e 2005, a força de trabalho feminina cresceu $12 \%$, chegando a $51,2 \%$ em 2005. De acordo com o relatório da Oficina da Presidência do Governo de 2006, 30\% deste crescimento deveu-se à imigração e ao emprego de mulheres imigrantes no trabalho doméstico. Entre 2003 e 2006, o papel das mulheres imigrantes no trabalho doméstico contribuiu com $50 \%$ do crescimento do nível de emprego feminino nativo pelo efeito das redes globais de cuidados. Juntamente com os fluxos de capital, informação e mercadorias, produzir-se-iam circuitos internacionais de cuidadoras que garantiam o cuidado dos filhos das imigrantes em seus países de origem, sob a tutela de outras mulheres que recebiam uma remuneração das mães enquanto estas se encontravam na Espanha cuidando de outras crianças, pessoas idosas ou dependentes (HERRERA MOSQUERA, 2012).

Entre 1994 e 2004, a população espanhola ampliou-se em 4,17 milhões de pessoas (10,7\%). Destes novos habitantes, $79,4 \%$ eram imigrantes. Tal crescimento demográfico foi fundamental para o aumento de $3,6 \%$ do PIB (1,5\% mais elevado do que a média dos países da União Europeia). Sem este incremento demográfico, o PIB não apenas teria ficado estancado, mas também teria sofrido uma queda anual de pelo menos 1\%. Em 2006, a Oficina Econômica da Presidência do Governo, assim como relatório emitido pelo Banco da Espanha ${ }^{2}$ ou de outras agências nacionais e estrangeiras, oferecia uma série de dados interessantes. Primeiramente, a quantificação da contribuição dos imigrantes ao crescimento econômico desde 2000 até 2006 representava 3,5\%. Concluiu-se que em torno de $50 \%$ dos imigrantes eram contribuintes do tesouro público. Em 2006 a quantia ascendia a 4,784 bilhões de euros, o que representava cifras de superávit. Ou seja, não se pode explicar a geração de riqueza na Espanha sem a imigração. Ademais, o aumento do trabalho feminino nativo tem um vínculo muito estreito com a chegada de mulheres estrangeiras na Espanha.

0 papel da imigração dentro do mercado de trabalho pode ser explicado com um termo confuso como o da flexibilidade. Quando os analistas não são mais precisos, referem-se à flexibilidade em termos de contratação: fluidez dos contratos, que às vezes têm um caráter ambíguo quando não são puramente verbais ou inexistentes. Referem-se também às condições de trabalho, ao salário e à mobilidade geográfica e funcional. Com frequência, entende-se por flexibilidade o mesmo que temporalidade. Se tomarmos tal característica como fator fundamental da flexibilidade, é difícil entender as queixas sobre a falta de flexibilidade quando a temporalidade é um elemento estrutural do mercado de trabalho espanhol (aproximadamente 35\% dos contratos têm esta característica). No entanto, a temporalidade dos contratos não é igualitária nos diversos grupos de imigrantes. $\mathrm{Ou}$ seja, trata-se de um fenômeno que tem caráter diferencial. Em 2006, a taxa de contratos indefinidos era de $66,2 \%$ entre o total de trabalhadores, mas correspondia a $42 \%$ entre os estrangeiros. Por sua vez, a taxa de contratados temporais era totalmente diferente: $33,8 \%$ no total da população trabalhadora e $58 \%$ entre os estrangeiros. Nesse caso, os

\footnotetext{
2 Banco de España - entidade reguladora da supervisão bancária e econômica na Espanha que, até a entrada em vigor da moeda comum europeia (euro), também tinha competências sobre política monetária no país. Corresponde, em parâmetros econômicos e regulatórios, ao papel desempenhado pelo Banco Central do Brasil.
} 
imigrantes provenientes da África se destacam de maneira muito chamativa, apresentando uma taxa de temporalidade de $69,47 \%$, mais de 10 pontos percentuais superior àquela para os demais continentes, embora tal situação possa ser explicada pelos tipos de ocupações desempenhados pelos imigrantes africanos, normalmente ligadas à agricultura e à construção, dois setores marcados pela elevada temporalidade das suas atividades.

Se analisarmos a nacionalidade das origens, entre os dez países de onde procedem mais imigrantes, destaca-se o Marrocos, com uma taxa de $67,84 \%$ de temporalidade. Tanto os dados por continente como por nacionalidade são inexplicáveis se não for considerado outro fenômeno estrutural de discriminação racial em relação aos imigrantes.

Os imigrantes presentes em setores fortemente afetados pela crise sofreram de modo mais direto as suas consequências em forma de desemprego. A taxa de desemprego sofre influência da crise, mas não restam dúvidas de que houve um impacto muito forte na taxa de temporalidade. Por esta razão, os grandes perdedores no mercado de trabalho foram, fundamentalmente, os africanos subsaarianos e também os marroquinos. Estes últimos apresentavam uma taxa de desemprego de $44,6 \%$ no começo de 2009 . Geralmente é um contingente formado por mão de obra masculina empregada na construção, agricultura e em postos sem qualificação do setor de serviços. Os imigrantes latino-americanos registravam taxas de desemprego entre $25 \%$ e $30 \%$, que são mais elevadas do que aquelas referentes aos nativos, mas consideravelmente inferiores às dos africanos. A explicação de tal situação é, em parte, porque esse grupo é formado em sua maioria por mulheres, que têm uma taxa de atividade mais elevada do que as mulheres africanas. As latino-americanas encontram emprego nos serviços domésticos e também na esfera do cuidado e atenção a pessoas, setor este que, como se sabe, sofreu menor impacto da crise do que os demais.

A título de conclusão, é necessário assinalar que, após vários anos de crise, a taxa de desemprego aumentou drasticamente entre os imigrantes. Entre 2008 e 2012, foram eliminados 727.000 postos de trabalho entre os estrangeiros. Tomando-se como base a variação da taxa de desemprego em 2008 e 2012, a diferença é muito elevada. De acordo com a EPA, em 2008 a taxa de desemprego entre a população imigrante era de $22,9 \%$, o que por si só já representava mais do que o dobro daquela referente aos nativos (10,2\%). Em 2012, essas taxas tinham aumentado para 36\% e 22,9\%, respectivamente. No primeiro trimestre de 2013 , as mesmas taxas eram de $39,2 \%$ e $25,1 \%$. Nota-se, portanto, que a taxa de desemprego continua sendo superior no caso dos trabalhadores estrangeiros.

Entre a população imigrante, a elevada temporalidade do emprego faz com que o desemprego neste grupo seja muito mais alto. Perante isso, o único sistema de sobrevivência consiste em tentar arranjar trabalho no que for possível. 0 aumento do desemprego ao logo dos quatro anos de crise implica um período maior entre a demissão de um emprego e a contratação por outro empregador. Portanto, o desemprego torna-se crônico com repercussões econômicas e sociológicas muito importantes. No entanto, é possível que o caráter crônico do desemprego dos imigrantes traga consigo a percepção, por parte dos nativos, de que já não jogam nenhum papel importante na economia espanhola como ocorria no período pré-crise. 
Nos nove últimos anos multiplicou-se por mais de seis o número de pessoas estrangeiras ativas na Espanha, proporcionando uma taxa de atividade de $77 \%$, que é pelo menos 20 pontos percentuais superior à da população espanhola, que ronda os $57 \%$. Com estas taxas de atividade é possível explicar que, embora a taxa de desemprego seja mais alta entre os imigrantes, a proporção de pessoas em idade de trabalhar sobre a população total é maior do que na população espanhola. Apesar disso, os salários dos imigrantes são bem menores do que os dos espanhóis.

De acordo com a Encuesta de Estructura Salarial de 2010, do INE, o ganho médio anual por trabalhador para a população espanhola era de 23.535,39 euros e, para os originários da América Latina, caía para 14.649,79 euros. Isso significa que o salário da população espanhola era $66 \%$ mais elevado do que o da população imigrante latino-americana. Os baixos salários também implicam uma participação importante dos imigrantes na economia informal. Embora não se conheça a dimensão exata das atividades econômicas informais, estimativas muito variadas quantificam-na entre $20 \%$ e $23 \%$ do PIB.

As áreas em que há maior concentração de mão de obra imigrante na economia informal são agricultura, construção, alguns setores da indústria manufatureira (têxtil, calçado e brinquedos) e, sobretudo, os serviços - restauração, limpeza, trabalho doméstico e tarefas de cuidados. Os trabalhos nestes setores constituem o único acesso a um posto de trabalho para imigrantes sem documentos exigidos para o exercício profissional na Espanha. Também há outros imigrantes que, mesmo dispondo de permissão de trabalho formal, acaba realizando tarefas informais, o que demonstra a precariedade das suas condições de trabalho, não contribuindo, portanto, para o sistema de Seguridade Social e, portanto, sem direitos.

Numa situação de precariedade e desemprego, a taxa de risco de pobreza para as pessoas maiores de 16 anos de nacionalidade estrangeira, em 2011, era de $25,8 \%$ no caso dos que procediam da União Europeia. Para os extracomunitários, essa taxa disparava para $44,2 \%$, segundo os dados definitivos da Encuesta de condiciones de vida (INE, 2014). A mesma pesquisa indicava que $33,2 \%$ das pessoas de nacionalidade estrangeira de mais de 16 anos e procedentes de países comunitários tinham dificuldade ou muita dificuldade para atravessarem o mês. No entanto, se eram imigrantes extracomunitários, mais da metade estava nessa situação (50,7\%) (Tabela 3$)$.

TABELA 3

Taxas de risco de pobreza, segundo grupos populacionais Espanha - 2004-2013

Em porcentagem

\begin{tabular}{lllllllllll}
\hline \multicolumn{1}{c}{ Grupos populacionais } & $\mathbf{2 0 1 3}$ & $\mathbf{2 0 1 2}$ & $\mathbf{2 0 1 1}$ & $\mathbf{2 0 1 0}$ & $\mathbf{2 0 0 9}$ & $\mathbf{2 0 0 8}$ & $\mathbf{2 0 0 7}$ & $\mathbf{2 0 0 6}$ & $\mathbf{2 0 0 5}$ & $\mathbf{2 0 0 4}$ \\
\hline Total & 19,3 & 21,0 & 21,0 & 20,4 & 19,2 & 19,5 & 18,7 & 19,2 & 19,2 & 20,6 \\
População espanhola & 16,5 & 18,5 & 19,0 & 18,7 & 17,8 & 17,9 & 17,6 & 18,2 & 18,6 & 20,2 \\
População estrangeira (UE) & 35,1 & 31,2 & 25,8 & 25,2 & 28,2 & 28,6 & 27,3 & 23,0 & 24,4 & 20,4 \\
População estrangeira (resto do mundo) & 47,8 & 46,0 & 44,2 & 38,3 & 31,6 & 34,7 & 30,4 & 31,9 & 28,9 & 30,3 \\
\hline
\end{tabular}

Fonte: INE - Instituto Nacional de Estatística (www.ine.es). 
Como consequência deste contexto, em 30 de abril de 2011 foi publicado o Regulamiento de Extranjería, que parece não levar em conta a situação de crise e como esta influencia diretamente no trabalho, salários, ou na vida dos imigrantes. Chama a atenção que, diante de uma conjuntura tão complexa como a que a Espanha está atravessando atualmente, reforça-se a falta de flexibilidade em vez de oferecer mecanismos para evitar uma situação de irregularidade, problema acarretado pela falta de trabalho e de seguro-desemprego.

Pouco depois das eleições gerais de 2011, o governo afirmou que "era necessário limitar o seguro social para tentar desencorajar a imigração irregular e incentivar a circulação e o retorno com possibilidade de regresso" (RODRÍGUEZ-PINA; PABLOS, 2011).

Como se observa, o desemprego gerado desde o início da crise tem afetado com muito mais intensidade a população imigrante. No entanto, o retorno aos seus países de origem ou uma nova emigração não se produziu de maneira imediata. 0 processo foi ganhando dimensão mais tarde, com o agravamento da situação gerada pela crise. Desse modo, os imigrantes vêm utilizando diversas estratégias para driblar a crise e a situação de penúria em que se encontram. Por exemplo, a incorporação ao mercado de trabalho de mais membros da família que estavam inativos até então ou alternando longas temporadas em seus lugares de origem e no de destino enquanto recebiam o seguro-desemprego, aproveitando a vantagem do euro em relação às moedas nacionais dos seus respectivos países, especialmente os que procediam de países mais próximos, como Marrocos ou Romênia, de onde provêm as maiores colônias de imigrantes presentes na Espanha na atualidade. Outra estratégia teve a ver com uma espécie de retrocesso nas condições de moradia de certas famílias de imigrantes ao alugarem suas casas a terceiros, passando para a condição de inquilinos em casas mais baratas, ou então alugando quartos da residência atual para outras famílias diante da queda brusca da renda familiar (ARANGO, 2009).

0 aumento do retorno de imigrantes aos seus países de origem é algo muito recente e ocorre apenas em virtude do agravamento da situação de crise econômica na Espanha. O programa Previe - Programa de Retorno Voluntario de Inmigrantes desde España, atendido por ONGs, deu cobertura a 1.800 pessoas em 2008, enquanto no final de 2013 havia 2.000 pessoas em lista de espera. Previamente, em 2007, tinha atendido 1.200 pessoas. 0 Ministerio de Trabajo e Inmigración iniciou, em 2008, um segundo programa que contabilizava 7.000 retornos um ano depois.

Esgotadas todas as estratégias de resistência e os recursos acumulados após anos de trabalho, os imigrantes então começaram a empreender o caminho do retorno, ao mesmo tempo que os espanhóis também começavam a emigrar em busca de oportunidades. Porém, essa diáspora trará efeitos negativos sobre a recuperação econômica pelos efeitos que provoca sobre a demografia e o consumo. Emigra a população jovem e preparada, o que significa envelhecimento demográfico, bem como a perda de certas pautas de consumo. Apesar da imagem de consumidores de serviços sociais, a contribuição dos imigrantes à economia formal foi superior ao seu gasto. 0 custo sanitário representa $5 \%$ e o de pensões, $1 \%$. Sem a contribuição dos imigrantes, a economia espanhola não teria crescido entre 
1998 e 2007 no ritmo em que ocorreu. A chegada de imigrantes permitiu passar de 39 milhões de habitantes para 45 milhões. Tal crescimento não foi resultado do investimento empresarial ou estrangeiro, mas sim do aumento do consumo como consequência do incremento da população (DE SEBASTIÁN, 2007).

A recuperação econômica exigirá a contratação futura de trabalhadores estrangeiros. Portanto, o recrutamento de novos imigrantes implicará custos econômicos e sociais que poderiam ser poupados se a política migratória fosse encarada como uma perspectiva de médio prazo. Desse modo, poder-se-ia recorrer a trabalhadores imigrantes entre os já residentes na Espanha. Ou seja, fomentar o retorno massivo de imigrantes poderia provocar mais prejuízos do que benefícios para a economia do país (MARTíNEZ VEIGA et al., 2006).

\section{Conclusões}

A imigração teve um efeito positivo sobre a economia e a geração de emprego na Espanha durante o período em que o país se tornou um polo de atração de mão de obra, sobretudo dos países latino-americanos e também do Leste Europeu, que representam as maiores comunidades de estrangeiros residentes no país.

Os níveis de desenvolvimento do recente passado do país não teriam sido possíveis sem o enorme avanço demográfico que possibilitou a chegada de milhões de trabalhadores estrangeiros. Em linhas gerais, sua presença não prejudicou o mercado de trabalho local. Pelo contrário, aumentou o número de contribuintes da Seguridade Social e permitiu ainda mais a entrada de mulheres no mercado laboral. As mulheres imigrantes ficaram responsáveis, na sua maioria, pelos trabalhos domésticos e cuidado de crianças, idosos e pessoas com algum tipo de incapacidade, o que sempre foi tradicional na cultura mediterrânica. 0 efeito da imigração sobre o conjunto da economia espanhola deve ser entendido de maneira positiva, já que sua contribuição econômica foi muito maior do que os gastos sociais que representa.

Os imigrantes formam o grupo social mais castigado pela crise econômica que se instalou na Espanha a partir da segunda metade dos anos 2000, que trouxe como consequência mais imediata a destruição dos seus postos de trabalho, especialmente devido ao elevado índice de temporalidade. Outra consequência da crise sobre os imigrantes foi tê-los tornado um grupo vulnerável, no qual a taxa de risco de pobreza e as dificuldades para sobreviver com um salário mensal são bastante elevadas.

Um dos fatores que explicam a elevada taxa de desemprego entre a população imigrante, em muito superior à média entre os cidadãos nativos, é a alta temporalidade dos seus empregos, principalmente em setores que têm sido castigados pela crise econômica, como é o caso da construção civil.

Os trabalhadores imigrantes que chegaram à Espanha massivamente a partir da segunda metade da década de 1990, etapa de rápido crescimento econômico, formam o grupo que mais está deixando o país. Uma parte deles já obteve a cidadania espanhola, mas o elevado 
índice de desemprego provocado pela grande recessão os força ao retorno para os seus países de origem ou então para outros países, uma vez que a nacionalidade espanhola lhes dá direito de procurarem emprego nos demais países que formam a União Europeia.

\section{Referências}

ADOLF, S. Mi casa, su casa: a la mesa con emigrantes españoles. Den Haag: De Nieuwe Haagsche, 2012.

ALAMINOS, A.; ALBERT, M. C.; SANTACREU, O. La movilidad social de los emigrantes españoles en Europa. Revista Española de Investigaciones Sociológica (Reis), n. 129, p. 13-35, 2012.

ALTED, A.; ASENJO, A. De la España que emigra a la España que acoge. Madrid: Fundación Largo Caballero, 2006.

ARAGÓN, J.; ROCHA, F. La crisis económica y sus efectos sobre el empleo en España. Madrid: Fundación $1^{0}$ de Mayo, 2012 (Colección Informes, n. 55).

ARANGO, J. Después del gran boom. La inmigración en la bisagra del cambio. In: AJA, E. et al. La Inmigración en tiempos de crisis. Barcelona: CIDOB, 2009.

ASOCIACIÓN DE CIENCIAS AMBIENTALES. Pobreza energética en España. Potencia de generación de empleo derivado de la rehabilitación energética de viviendas. Madrid: Asociación de Ciencias Ambientales, 2012.

ATIENZA AZCONA, J. Las migraciones del siglo XXI. Documentación Social, Madrid, n. 147, p. 29-45, 2007.

COSTAS, A. Raquitismo empresarial. El País, 20 enero 2013. Disponível em: 〈http://www. caffereggio.net/2013/01/20/raquitismo-empresarial-espanol-de-anton-costas-en-negociosde-el-pais/>.

ESPANHA. Ministerio de Agricultura, Alimentación y Medio Ambiente. El consumo alimentario en España año 2011. Madrid, 2012.

ESPAÑOLES EN FINLANDIA. Carta de España, n. 666, diciembre 2010.

FERNÁNDEZ ASPERILLA, A. Repensar las migraciones femeninas. Revista de Estudios, n. 14, p. 34-36, 2010.

FUNDACIÓN 1ํ DE MAYO. Trabajadores pobres y empobrecimiento en España. Madrid, 2012 (Colección Estudios, n. 56).

Empobrecimiento de la población en España. Encuesta de Condiciones de Vida. Madrid, octubre 2012 (Informes de la Fundación, n. 53).

GONZÁLEZ ENRIQUEZ, C. La emigración desde España: una migración de retorno. Madrid: Real Instituto Elcano, 2012.

HERRERA MOSQUERA, G. Repensar el cuidado a través de la migración internacional: mercado laboral, Estado y familias transnacionales en Ecuador. Cuadernos de Relaciones Laborales, n. 30, p.139-159, 2012.

INE - Instituto Nacional de Estadística. Encuesta de Condiciones de Vida 2011. Madrid, 2012.

Encuesta de Estructura Salarial 2010. Madrid, 2011.

Encuesta de Condiciones de Vida 2013. Resultados definitivos. Madrid, 2014.

Encuesta de Población Activa. I trimestre 2013. Madrid, 2013. 
Flujos de emigración e inmigración. Serie 2010-2011. Madrid, 2012.

. Padrón de habitantes 2009-2013. Disponível em: 〈http://www.ine.es/jaxiBD/menu. do? $\mathrm{L}=0$ \&divi $=$ EPOB\&his $=0$ \&type $=\mathrm{db}$.

Padrón de Españoles Residentes en el Extranjero (PERE). 2009-2013.

IZQUIERDO, A. La migración de la memoria histórica. Barcelona: Fundación F. Largo Caballero, Ediciones Bellaterra, 2011.

KLEIN, H. S. Los inmigrantes latinoamericanos en España y en Estados Unidos: un análisis comparativo a partir del American Community Survey y la Encuestas Nacional de Inmigrantes de 2007. Revista Política y Sociedad, n. 23, 2010.

LAGO PEÑAS, J. M. Un análisis cuantificado de los efectos de la reforma laboral sobre el empleo. Madrid: Fundación 1o de Mayo, 2013 (Colección Estudios, n. 61).

LÓPEZ DE LERA, D. Estratefias de retorno en época de crisis: la situación española. In: CONGRESO DE ASOCIACIÓN LATINOAMERICANA DE POBLACIÓN - ALAP. La Coruña, Universidad de La Coruña, 2012.

MARTÍNEZ VEIGA, U. (Dir.). Situaciones de exclusión de los emigrantes españoles ancianos en Europa. Paris: FACEEF, 2010.

. Los inmigrantes en el mercado de trabajo. In: ALTED, A.; ASENJO, A. (Coords.). De la España que emigra a la España que acoge. Madrid: Fundación F. Largo Caballero, 2006.

NOGUEIRA, C. Vamos a menos. El País, 19 nov. 2012.

OCDE. Doing better for families Spain. Disponível em: «http://www.OECD.org/spain/47704081. pdf . Acesso em: 20 abr. 2014.

RED EUROPEA DE MIGRACIONES (EMN). Glosario 2.0 sobre migración y asilo: un instrumento para una mayor comparabilidad. Luxemburgo: Unión Europa, 2012.

REHER, D.; REQUENA, M.; SANZ, A. ¿España en la encrucijada? Consideraciones sobre el cambio de ciclo migratorio. Revista Internacional de Sociología, n. 1, 2011.

ROCHA, F. El desempleo juvenil en España. Situaciones y recomendaciones políticas. Madrid: Fundación 10 de Mayo, 2012 (Colección Informes, n. 50).

ROCHA, F.; ARAGÓN, J. La crisis económica y sus efectos sobre el empleo en España. Madrid: Fundación 1ํ de Mayo, 2012 (Colección Informes, n. 55).

RODRÍGUEZ-PINA, G.; PABLOS, S. P. de. El PP impedirá la regularización de inmigrantes por arraigo social. El País, 24. nov. 2011. Disponível em: 〈http://politica.elpais.com/politica/2011/11/24/ actualidad/1322125831_984714.html>. Acesso em: 25 abr. 2014.

RUMÍ, C. La política del gobierno en materia de inmigración y emigración. In: ALTED, A.; ASENJO, A. (Coords.). De la España que emigra a la España que acoge. Madrid: Fundación Largo Caballero, 2006.

SÁNCHEZ ALONSO, B. El final del ciclo emigratorio español: desiderátum. Historia y Política, n. 23, p. 135-162, 2010.

SEBASTIÁN, L. de. La vinculación de la emigración y el desarrollo. Documentación Social, n. 147, p. 45-61, 2007.

SERVICIO EUROPEO DE EMPLEO (EURES). Informe de Actividades de la Red EURES España. Junio de 2010 a mayo de 2011. Disponivel em: 〈http://www.sepe.es/contenidos/personas/ encontrar_empleo/encontrar_empleo_europa/pdf/informe_anual_2012_13.pdf〉. 


\title{
Sobre 0 autor
}

Nilton Cezar Pereira Pinto é doutor em História Contemporânea pela Universidade Rey Juan Carlos (Madrid, Espanha). Pesquisador independente.

\section{Endereço para correspondência}

\author{
Calle Torremolinos, 6, 1으 B \\ 28018 - Madrid, Espanha
}

\begin{abstract}
The impact of the Spanish economic crisis on immigrant labor in Spain

This paper aims to analyze the situation of immigrant labor in Spain over the last ten years, linking it to social and economic transformations, which the country has undergone since the mid-1990s, with emphasis on the scenario generated by the economic crisis that erupted at the end of 2008 and its impact on the situation of immigrants, the people who have been most deeply affected by the new economic and social setting resulting from the crisis. Faced with the situation in Spain, with a remarkable increase in unemployment and deterioration of social indicators, immigrants have been returning to their countries of origin after exhausting all alternative ways to remain in Spain. The development of this paper is based on data provided by the Instituto Nacional de Estadística (INE - National Statistics Institute), of Spain, which used the Encuesta de Población Activa (EPA - Active Population Survey), in addition to data from Eurostat and the bibliographical references cited.
\end{abstract}

Keywords: Immigration. Economic crisis. Spain. Return. Unemployment.

\section{Resumen}

\section{El impacto de la crisis económica española en la mano de obra inmigrante}

Este artículo tiene por objetivo analizar la situación de la mano de obra inmigrante en España en los últimos diez años, vinculándola con las transformaciones económicas y sociales por las que ha atravesado el país desde mediados de la década de 1990, con énfasis en el panorama generado por la crisis económica que eclosionó a fines de 2008 y su impacto en la situación de los inmigrantes, colectivo que más ha sufrido con el nuevo escenario económico y social establecido con la crisis. Ante la situación por la que atraviesa España, con un notable aumento del desempleo y del deterioro de los indicadores sociales, se observa un considerable retorno de los inmigrantes hacia sus países de origen, después de agotar todas las vías alternativas para su permanencia. El fundamento para el desarrollo de este trabajo han sido los datos proporcionados por el Instituto Nacional de Estadística (INE) de España, utilizando la Encuesta de Población Activa (EPA), además de los datos de Eurostat y de las fuentes bibliográficas citadas.

Palabras clave: Inmigración. Crisis económica. España. Retorno. Desempleo. 
